MARJORIE WALLACE

\title{
Commentary: The SANE response
}

It does not require much insight to identify to whom $\mathrm{Dr}$ Persaud refers in his article 'Psychiatrists suffer from stigma too'. There is only one charity with an acronym, founded and run by a journalist, among those whom he alleges uses 'contacts and friendships' to monopolise the media.

However, Dr Persaud does raise some important issues regarding the media and psychiatrists. Relations have never been easy. In a volatile field where there are few certainties, no proof and increasingly polarised attitudes, it is inevitable that the press are confused and turn to 'outsiders' for comment. It is also unfortunate that in an area where there is so much conflict and pain, psychiatrists are often made public scapegoats when things go wrong.

But what Persaud forgets is that it is only recently that the stigma was so strong that it prevented national press, radio and television from mentioning the subject of mental illness at all. Fifteen years ago, when I wrote a series of articles for The Times there were no hungry media seeking comment or stories from anyone. Indeed, it took three years to persuade my own editors to break such taboos. Mental illness was regarded as dowdy and downbeat. When interviewees were persuaded to talk we had to use false names and silhouette photographs. Few people were prepared to speak out, including psychiatrists, who, with some notable exceptions, appeared to have turned a blind eye to the growing scandals resulting from the poorly implemented and underfunded policy of closure of the hospitals and abandoning severely ill people to squalid lodgings or to families who often broke down under the strain.

We were then a small, beleaguered resistance group consisting of angry families, neglected patients and some crusading doctors and other frontline workers, fighting for recognition of the scale of suffering against blinkered cost-driven policies. There was, and still is, a great temptation for those doing well in their profession to forget the casualties and smooth over the thornier issues which tear at the heart of mental health policy. This may, importantly, reassure some readers of Cosmopolitan and the tabloids, but does little to bring about the radical changes in mental health services and infusion of new monies, which have mainly resulted from the campaigning efforts of the very charities Dr Persaud decries.

The extraordinary assumption which underpins $\mathrm{Dr}$ Persaud's argument is that while he can cross boundaries and become a 'qualified' and, it appears from his output, nearly full-time journalist, lesser polymaths, especially journalists are unqualified or unable to understand professional issues and are therefore forbidden from venturing onto Dr Persaud's own patch. Yet one would hope by now he would have respected that the duty and skill of a serious journalist is to investigate complex subjects, distil and assess the many points of view and shape clear messages for professionals and public alike. Would he recommend that only politicians comment on politics, bishops on religion, architects on design? And that we leave all war reporting to Major Generals? In any case, the priority of a doctor, must be to commit maximum time and effort to the care of patients and their families, which as Dr Persaud points out, makes him or her less available to handle the press.

So, who should spearhead reforms in mental health policies and with what authority? SANE's messages are based on the views of approximately 1000 people a week who call our helpline, SANELINE. Two-thirds are those seeking help for themselves, the remainder of calls are from families, friends and professionals involved with their care. Over seven years we have kept anonymous records of every call where the caller has offered information, giving us enormous samples (in excess of 120000 ) which we continually analyse and from which we can identify their major needs, perceptions and concerns. Is it surprising that there are occasions when the media turn to groups like us who can give a broader, national view based on the experiences of more people than Dr Persaud is likely to see in a lifetime?

Marjorie Wallace Chief Executive, SANE, First Floor, Cityside House, 40 Adler Street, London E1 1 EE 